\title{
Carta al editor: Tratamiento del hipoparatiroidismo con hormona paratiroidea $(\mathrm{PTH})$
}

\section{Doctor}

Enrique Ardila Ardila

Editor

Revista Colombiana de Endocrinología, Diabetes y Metabolismo
Apreciado Dr. Ardila:

$\mathrm{H}$ e leído con interés la muy completa revisión de los doctores Esteban Cardona, Carlos Alfonso Builes Barrera y Alejandro Román González, titulada Tratamiento del hipoparatiroidismo con hormona paratiroidea ${ }^{(1)}$, la cual fue publicada en su prestigiosa revista. A través de su digno conducto, quisiera preguntarles a los autores ¿cuál es la experiencia colombiana (si la hay) con alguno o con ambos preparados de parathormona como suplencia hormonal en hipoparatiroidismo? Además, quisiera saber si Forteo ${ }^{\circledR}$ (teriparatida o PTH 1-34) o Natpara ${ }^{\circledR}$ (PTH 1-84) se consiguen a través de formulación con las EPS.

En los Estados Unidos se comercializa el Forteo ${ }^{\circledR}$, una ampolla con dosis para uso subcutáneo una vez al día, suficientes para 1 mes; su precio es de 4000 dólares. No he podido encontrar en las farmacias, ni conocer el precio del producto comercial Natpara ${ }^{\circledR}$ (PTH 1-84) de Shire Plc, que parece ofrecer ventajas. La indicación de suplencia para hipoparatiroidismo crónico (tetania por 6 meses o más) no está aprobada por la FDA; sin embargo, como bien se muestra en la revisión, Powers y colaboradores encontraron una prevalencia en los Estados Unidos de cerca de 59000 pacientes $^{(2)}$. La prevalencia en otros países es un poco más baja.

Como los investigadores han encontrado mejores resultados en calidad de vida y estabilización de la calcemia aplicando la mitad de la dosis 2 veces al día (la vida media es de 12 ho- ras, cuando se aplica en el muslo, pues allí la absorción es más lenta), no sé si sea posible lograrlo con la presentación actual.

El hipoparatiroidismo idiopático es una entidad muy rara. En mi experiencia, tuve un caso con calcificaciones de los núcleos basales que fue objeto de una publicación. El grupo de la Universidad Nacional también tuvo algunos casos; y esa sería la primera indicación para la suplencia. Menos infrecuente es el hipoparatiroidismo idiopático luego de la tiroidectomía, aunque afortunadamente es transitoria en alrededor del $75 \%$ de los casos.

Últimamente se ha incrementado el número de pacientes sometidos a paratiroidectomia (única, doble o de las 4 paratiroides, dejando parte de una para las hiperplasias) y, por ende, el de los casos de hipoparatiroidismo, a veces permanente (por más de 6 meses) en ausencia de respuesta de las paratiroides que quedan. La alta cantidad de tabletas de calcio y de calcitriol para controlar la tetania, con todos los efectos secundarios que esta terapia acarrea, hace deseable, aunque muy costosa, la suplencia con PTH. Además, es preocupante la posibilidad de nefrocalcinosis y de intoxicación con vitamina D. Hace años tuve un caso de estos últimos en una paciente con hipoparatiroidismo crónico posquirúrgico, que pude sacar adelante con el manejo recomendado.

Aunque no es precisamente el tema, me gustaría saber si los autores conocen un centro colombiano en el que se practique rutinariamente la cirugía mínimamente invasiva para los casos, cada vez más frecuentes, de hiperparatiroidismo primario.

Atentamente,

Dr. Alfredo Jácome Roca Médico Internista-Endocrinólogo Ocala, Florida, Estados Unidos 


\title{
Referencias
}

1. Cardona E, Builes-Barrera CA, Román-González A. Tratamiento del hipoparatiroidismo con hormona paratiroidea. Rev Colomb Endocrinol Diabetes Metab. 2019;6(1):35-41.

2. Powers J, Joy K, Ruscio A, Lagast H. Prevalence and incidence of hypoparathyroidism in the United States using a large claims database. J Bone Miner Res Off Am Soc Bone Miner Res. 2013;28(12):2570-6.

\section{Respuesta del autor para la carta al editor}

\author{
Apreciado doctor Jácome:
}

Muchas gracias por sus comentarios. Procedo a contestarle punto por punto.

- No existe experiencia publicada con PTH; actualmente, estamos desarrollando el trabajo. En relación con Forteo ${ }^{\circledR}$, por mi parte, tengo dos pacientes; el doctor Johnayro Gutiérrez tiene dos pacientes; y el doctor Henry Mauricio Arenas tiene un paciente. En EPS Sura, la doctora Sandra Mora tiene un paciente con Natpara ${ }^{\circledR}$. De acuerdo con lo que hemos preguntado a los distintos colegas, es posible que no hayan más de 20 pacientes en Colombia.

- $\quad$ Forteo $^{\circledR}$ se consigue por medio de la EPS, pero la indicación es osteoporosis. La mayoría de los casos de hipoparatiroidismo se han justificado con un con diagnóstico de osteoporosis. El caso de Natpara ${ }^{\circledR}$ es más complejo, porque no está disponible en Colombia y se debe solicitar su importación como vital no disponible, con un costo mensual de 11 a 14 mil dólares aproximadamente.
- Es difícil que autoricen el uso de Forteo ${ }^{\circledR}$ dos veces al día en Colombia, porque no tiene aprobación del Invima en esa dosis.

- No conozco quién realice la cirugía mínimamente invasiva para paratiroides. El doctor Álvaro Sanabria ha intentado un abordaje con tiempos más cortos de cirugía. En mi caso, y lo que he aprendido con el doctor Latorre, algunos pacientes con seguros médicos internacionales, como la Póliza Global Sura, se pueden remitir al Centro Norman de Paratiroides en Florida (https://www.parathyroid.com/ about-parathyroid.htm).

Muchas gracias por leer profundamente nuestro artículo. Esperamos presentar pronto los resultados de un estudio de corte transversal de hipoparatiroidismo.

Cordialmente,

Alejandro Román-González, MD

Endocrinología Clínica y Metabolismo

Hospital Universitario San Vicente Fundación

Profesor Universidad de Antioquia

Medellín, Colombia. 